\title{
Off-label prescription of fixed-dose combination of tramadol and dexketoprofen in primary health care. Evidence-based or cause for concern?
}

Montserrat Viñas-Bastart

University of Barcelona: Universitat de Barcelona

Míriam Oms-Arias

Institut Catala De La Salut

Africa Pedraza-Gutiérrez

Institut Catala De La Salut

Irene Lizano-Díez

University of Barcelona: Universitat de Barcelona

Eduardo L. Mariño

University of Barcelona: Universitat de Barcelona

Pilar Modamio ( $\nabla$ pmodamio@ub.edu )

Universidad de Barcelona: Universitat de Barcelona https://orcid.org/0000-0003-3193-6285

\section{Research Article}

Keywords: Off-label prescribing, opioid, pharmacoepidemiology, primary health care, tramadol, dexketoprofen drug combination

Posted Date: March 26th, 2021

DOl: https://doi.org/10.21203/rs.3.rs-359408/v1

License: (9) This work is licensed under a Creative Commons Attribution 4.0 International License. Read Full License 


\section{Abstract}

Background: The increase of consumption of the fixed-dose combination of tramadol/dexketoprofen in Spain and other countries is noteworthy. The authorised therapeutic indication is symptomatic short-term treatment of moderate to severe acute pain in adult patients.

Objective: Describe the pattern of use of tramadol/dexketoprofen in the field of primary health care to examine potential off-label prescribing and warn about possible risks.

Methods: A descriptive, cross-sectional and multicenter study carried out between March 2017 and March 2018. Total population were patients covered by the public health service in Catalonia, Spain, with an active prescription of tramadol/dexketoprofen on March 28, 2018. Target population were those patients who were prescribed tramadol/dexketoprofen over 20 day's treatment.

Results: There were 176 patients with active prescription of tramadol/dexketoprofen. All patients (100\%) had a treatment duration exceeding 5 days and $72.7 \%(\mathrm{~N}=128)$ exceeding 20 days. The average length of treatment was $224 \pm 160.8$ days. $35.1 \%$ of patients were treated with $>2$ medicines for pain concomitantly with tramadol/dexketoprofen.

Conclusion: Tramadol/dexketoprofen fixed-dose combination in practice was used frequently off labelled according to the product characteristics and the literature reviewed. This study highlights potential harmful or ineffective effects of this combination since no adequate evidence exists about its off-label use.

\section{Impacts On Practice}

- Off-label prescribing of the fixed-dose combination of tramadol and dexketoprofen is common, despite lacking evidence of efficacy and potentially increasing risk for adverse drug events.

- Tramadol/dexketoprofen should be prescribed with a diagnosis associated with acute pain and for the five days authorised according to the product characteristics.

- Two thirds of the prescriptions came from the general practitioners and interventions directed at them are needed to promote an appropriate use.

\section{Introduction}

The estimated prevalence of chronic pain in the US is 11\% [1] and 19\% in Europe [2]. Not only the US [3] but also some European countries such as Germany [4] and United Kingdom [5] have shown a significant increase in the consumption of opioid analgesics and the trends in mortality due to opioid poisoning pointing out similarities to the US. So far, the key points that have raised are the increased risk of misuse (diversion), overdose, death, abuse, dependence, bone fractures, myocardial infarctions, constipation and sexual dysfunction [6]. 
A recent study about the prescribing patterns of opioids from 2013 to 2017 in one of the main health administrative regions in Portugal showed an increase approximately 1.5 -fold over a 4-year period (2013-2017) [7]. In Spain, the use of opioids for the period 2008-2015 [8] went from 7.3 defined daily doses (DDD) per 1,000 inhabitants per day to 13.3.

The appearance on the market of tramadol/dexketoprofen $75 \mathrm{mg} / 25 \mathrm{mg}$ film-coated tablets in 2016 and the increase of consumption in 2017 are noteworthy [9]. According to its summary of product characteristics (SmPC) [10] the authorised therapeutic indication is symptomatic short-term treatment of moderate to severe acute pain in adult patients whose pain is considered to require a combination of tramadol and dexketoprofen. The recommended dosage is one tablet with a minimum dosing interval of 8 hours, without exceeding three tablets per day and five days of treatment. Switching to a single agent analgesia should be considered according to pain intensity and response of the patient.

Despite the progressive change and the increasing use observed that can impact of pain as a public health issue, there have not been published studies on the use of the combination tramadol/dexketoprofen in clinical practice.

\section{Aim}

We aimed to describe the pattern of use of fixed-dose combination of tramadol/dexketoprofen in the field of primary health care to examine potential off-label prescribing and warn about possible risks and suggest interventions.

\section{Ethics Approval}

Ethical approval was not required as it was made a secondary analysis in accordance with Spanish regulations.

\section{Methods}

A descriptive, cross-sectional and multicenter study was carried out between March 2017 and March 2018. It covered the 53 primary health care teams and 4 primary care services in the Department of Primary Care (DAP) Costa de Ponent of the Catalan Institute of Health (ICS), which provides health care for 1.3 million inhabitants in the southern Barcelona Metropolitan Area (Catalonia, Spain) [11].

Total population were patients covered by the DAP Costa de Ponent with an active prescription of tramadol/dexketoprofen on March 28, 2018 (cut-off date chosen as a cross sectional data to provide a snapshot of drug use at a day). Target population were those patients who were prescribed tramadol/dexketoprofen over 20 day's treatment, since it was considered 20 days as the limit for a shortterm treatment of acute pain. 
The computerized health records of patients with active tramadol/dexketoprofen prescription were selected from the e-CAP computer program, and extracted from anonymized data.

The variables studied were demographic (age, sex) and clinical (prescribers' specialty; characteristics of the study drug (combined tramadol/dexketoprofen) regarding indications, dosing and duration of treatment; diagnoses of target patients; previous analgesic treatment and concomitant analgesic treatment).

A descriptive statistical analysis of the data was carried out. Discrete variables were published as proportions or frequencies and continuous variables as means and standard deviations.

\section{Results}

On the cut-off date, there were 176 patients with active prescription of tramadol/dexketoprofen. All these patients $(100 \%)$ had a treatment duration exceeding 5 days and $72.7 \%(\mathrm{~N}=128)$ exceeding 20 days; $73.4 \%$ of them $(\mathrm{N}=94)$ were women. Figure $1(\mathrm{a}-\mathrm{d})$ shows the distribution of patients according to the origin of prescriptions, dosing, duration of treatment and diagnoses.

Twelve patients did not have any diagnosis specified at e-CAP. Table 1 shows in detail the diagnoses classified as "Other" in Fig. 1d. Only three patients out of $176(1.7 \%)$ had a treatment associated with an oncological diagnosis. 
Table 1

Distribution of patients according to "Other" diagnoses

ICD code Other diagnoses

Number of patients

(\%)

M25.5 Pain in joint

$2(1.6)$

M72.2 Plantar fascial fibromatosis

$2(1.6)$

M70.6 Trochanteric bursitis

$2(1.6)$

M93 Other osteochondropathies

$2(1.6)$

R10.3 Pain localized to other parts of lower abdomen

$1(0.8)$

R53.82 Chronic fatigue, unspecified

$1(0.8)$

G43.1 Migraine with aura

$1(0.8)$

G93.3 Postviral fatigue syndrome

$1(0.8)$

M89.00 Algoneurodystrophy, unspecified site

$1(0.8)$

G62.9 Polyneuropathy, unspecified

$1(0.8)$

S43.001 Unspecified subluxation of right shoulder joint

$1(0.8)$

S42.0 Fracture of clavicle

$1(0.8)$

S12.0 Fracture of first cervical vertebra

$1(0.8)$

T07 Unspecified multiple injuries

$1(0.8)$

F32.2 Major depressive disorder, single episode, severe without psychotic $1(0.8)$ features

M06.9 Rheumatoid arthritis, unspecified

$1(0.8)$

F90 Attention-deficit hyperactivity disorders

$1(0.8)$

F41.9 Anxiety disorder, unspecified

$1(0.8)$

E03.9 Hypothyroidism, unspecified

$1(0.8)$

E79.0 Hyperuricemia without signs of inflammatory arthritis and

$1(0.8)$ tophaceous disease

N18.9 Chronic kidney disease, unspecified

$1(0.8)$

187.2 Venous insufficiency (chronic) (peripheral)

$1(0.8)$

M25.562 Pain in left knee

$1(0.8)$

J31.1 Chronic nasopharyngitis

$1(0.8)$

Z96.69 Presence of other orthopedic joint implants

$1(0.8)$ 


\begin{tabular}{|lll|}
\hline ICD code & Other diagnoses & $\begin{array}{l}\text { Number of patients } \\
(\%)\end{array}$ \\
\hline C56 & Malignant neoplasm of ovary & $1(0.8)$ \\
\hline M65.0 & Abscess of tendon sheath & $1(0.8)$ \\
\hline M75.0 & Adhesive capsulitis of shoulder & $1(0.8)$ \\
\hline M62.40 & Contracture of muscle, unspecified site & $1(0.8)$ \\
\hline M77.9 & Enthesopathy, unspecified & $1(0.8)$ \\
\hline M54.1 & Radiculopathy & $1(0.8)$ \\
\hline M65.2 & Calcific tendinitis & $1(0.8)$ \\
\hline S52.502 & Unspecified fracture of the lower end of left radius & $1(0.8)$ \\
\hline M80.9 & Unspecified osteoporosis with pathological fracture & $1(0.8)$ \\
\hline
\end{tabular}

Concerning medication prior to tramadol/dexketoprofen associated with the treatment of pain, $14.1 \%$ of patients $(\mathrm{N}=18)$ had not taken any medication for pain before. In contrast, $18.8 \%(\mathrm{~N}=24)$ had been previously treated with one medication for pain, $25.8 \%(\mathrm{~N}=33)$ had been previously treated with 2 drugs and $41.4 \%(\mathrm{~N}=53)$ had been previously treated with more than two drugs. Finally, $7.8 \%$ of patients $(\mathrm{N}=$ 10) had been previously treated with tramadol and dexketoprofen separately.

Regarding the associated pain medication prescribed concurrently with tramadol/dexketoprofen, $14.1 \%$ of patients $(\mathrm{N}=18)$ had not ever taken any medicine for pain at any time during treatment with tramadol/dexketoprofen. $26.6 \%$ of patients $(\mathrm{N}=34)$ had been treated with one medicine for pain in addition to tramadol/dexketoprofen, $24.2 \%(\mathrm{~N}=31)$ with two and $35.1 \%$ of patients $(\mathrm{N}=45)$ with more than two. Table 2 shows the active substances and/or therapeutic groups that had been prescribed concurrently with tramadol/dexketoprofen. 
Table 2

Drug treatment in combination with tramadol/dexketoprofen

\begin{tabular}{|c|c|c|}
\hline Active substances and therapeutic groups & Number of drugs & $\% *$ \\
\hline Analgesics ${ }^{a}$ & 90 & 70.3 \\
\hline Weak opioids ${ }^{\mathrm{b}}$ & 47 & 36.7 \\
\hline Antiepileptics/Analgesics ${ }^{c}$ & 46 & 35.9 \\
\hline $\mathrm{NSAIDs}^{\mathrm{d}}$ & 42 & 33.1 \\
\hline Skeletal muscle relaxants ${ }^{\mathrm{e}}$ & 24 & 18.8 \\
\hline Lidocaine & 10 & 7.8 \\
\hline Corticosteroids ${ }^{f}$ & 9 & 7.0 \\
\hline Sumatriptan & 2 & 1.6 \\
\hline Fentanyl & 1 & 0.8 \\
\hline \multicolumn{3}{|c|}{ 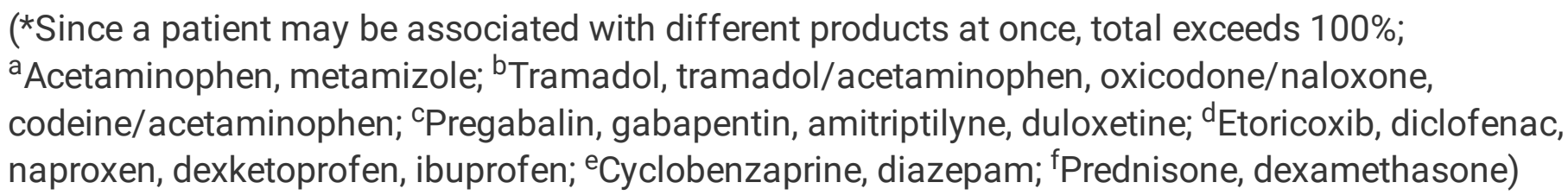 } \\
\hline
\end{tabular}

\section{Discussion}

Current evidence indicates that opioids should not be used as first line therapy, but only when all other treatment options have been tried and failed [12]. The National Institute for Health and Care Excellence's (NICE) found no evidence of long-term effectiveness in chronic non-cancer pain treatment, despite its analgesic effect in the short-term. [13] Furthermore, prescribing of opioids for acute indications such as surgical pain in opioid-naïve patients can also lead to a transition to chronic opioid therapy. [5]

A higher percentage of women with active prescription and an average age of 54.7 years were expected data since the prevalence of pain for more than three months is more common in women and in people over 65 years old in Spain.

Exploring the origin of the prescriptions, most of them came from the general practitioner, when a prescription by a specialist would be advisable [14]. The influence of general practitioner on the dissemination of opioids is substantial to promote an appropriated use. Insufficient training and information about opioid management protocols, time pressure to assess patients properly and systemlevel constraints such as limited access to specialized and integrative care are some of the reasons that could explain the off-label prescription of opioids [14]. 
About the duration of treatment, $36.7 \%$ of patients had a prescription with durations between 9.5 and 12 months. According to the SmPC of tramadol/dexketoprofen [10], it is intended only for short-term use and treatment should be limited strictly to the symptomatic period (5 days). Although in our study, only three patients had post-surgical pain treatment and for 10 days, several studies of chronic postsurgical pain [14] showed that if postoperative pain is not managed properly, it could evolve in chronic pain, becoming a serious problem. In addition, in the absence of evidence on the efficacy and safety of long-term opioid use, it is recommended to re-evaluate at three months the opioid treatment [12].

In relation to the diagnoses found, tramadol/dexketoprofen was hardly used in cancer pain management or in the context of palliative care what is a cause of concern considering the long-term treatment observed (more than 300 days) in $43 \%$ of patients. In reference to the most common diagnoses (primary osteoarthritis, low back pain, fibromyalgia and lumbago with sciatica), nociceptive pain was highly prevalent and should be treated with analgesics and anti-inflammatory drugs. Although long-term opioid treatment has not yet been widely studied on a population basis, many patients may tolerate and respond to this treatment, and it should not be denied to them, with a close follow-up in terms of effectiveness and safety. [15]

It was also found that $26.6 \%$ of patients with tramadol/dexketoprofen prescription had been treated concomitantly with one of the two components of this drug, which was unable to account for.

Interventions to improve prescribing should be carried out since there are numerous contraindications and precautions related to tramadol/dexketoprofen, as well as risk of tolerance and addiction [10]. In this sense, some interventions could be that patients had an assessment of their pain and their perspectives regarding the use of this drug (and opioids in general), and physician considered them to promote their correct use, specially preventing their misuse [12]. Another possibility could be to make a reminder to physicians about the indications of tramadol/dexketoprofen and provide information about the inadequate diagnoses and/or prolonged use in chronic noncancer pain, and alternatives in such cases according to evidence [5].

\section{Conclusion}

The present study points out that tramadol/dexketoprofen is frequently used off-label, as treatments were usually prescribed without a diagnosis associated with acute pain and were lengthened beyond the days authorised and in most cases 4 times longer than the time period indicated. These results warn about potential harmful or ineffective effects ("concern") of tramadol/dexketoprofen combination since no adequate evidence exists about its off-label use. Interventions to improve tramadol/dexketoprofen prescribing for the treatment of moderate-to-severe acute pain are needed.

\section{Declarations}


Funding: This research received no specific grant from any funding agency in the public, commercial or not-for-profit sectors

Conflicts of interest/Competing interests: All the authors have disclosed that they have no significant relationships with or financial interests in any commercial companies related to this study or article.

Availability of data and material: Data used in this study are available from the corresponding author upon reasonable request.

Code availability: Not required.

Author's contributions: Study concept and design: MO-A, ELM, and PM. Acquisition of data: MV-B and APG. Analysis and interpretation of data: MV-B, MO-A, AP-G, IL-D, ELM, and PM. Drafting of the manuscript: $M V-B, A P-G$, and IL-D. Critical revision of the article for important intellectual content: MO-A, IL-D, ELM, and PM. All the authors have read and approved the manuscript.

Ethics approval: Not required.

Consent to participate: Not required.

Consent for publication: Not required.

\section{References}

1. Nahin RL. Estimates of pain prevalence and severity in adults: United States, 2012. J Pain. 2015;16:769-80.

2. Breivik $\mathrm{H}$, Collett $B$, Ventafridda $V$, et al. Survey of chronic pain in Europe: prevalence, impact on daily life, and treatment. Eur J Pain. 2006;10:287-333.

3. Guy GP, Zhang K, Bohm MK, et al. Vital signs: Changes in opioid prescribing in the United States, 2006-2015. MMWR Morb Mortal Wkly Rep. 2017;66:697-704.

4. Schubert I, Ihle P, Sabatowski R. Increase in opiate prescription in Germany between 2000 and 2010: a study based on insurance data. Dtsch Arztebl Int 2013;110:45-51.68.

5. 18. Alenezi A, Yahyouche A, Paudyal V. Current status of opioid epidemic in the United Kingdom and strategies for treatment optimisation in chronic pain. Int J Clin Pharm (2020). https://doi.org/10.1007/s11096-020-01205-y.

6. Downes JM, Klepser DG, Foster J, et al. Development of a standardized approach for managing opioids in adults with chronic noncancer pain. Am J Health Syst Pharm. 2018;75:321-6.

7. Caldeira D, Broeiro P, Cimadeira F, et al. Opioids prescribing trend between 2013 and 2017 in the Lisbon and Tagus Valley region, Portugal. Int J Clin Pharm. 2020. https://doi.org/10.1007/s11096020-01199-7. 
8. The Spanish Agency of Medicines and Medical Devices. [Report on the use of medicines. Use of opioid medicines in Spain during the period 2008-2015]. Report. U/OPI/V1/13022017. Available: https://www.aemps.gob.es/medicamentosUsoHumano/observatorio/docs/opioides-2008-2015.pdf. [Accessed 12 February 2021].

9. Varrassi G, Hanna M, Macheras G, et al. Multimodal analgesia in moderate-to-severe pain: a role for a new fixed combination of dexketoprofen and tramadol. Curr Med Res Opin. 2017;33:1165-73.

10. The Spanish Agency of Medicines and Medical Devices. Enanplus $\AA^{7} 75$ mg/25 mg film-coated tablets. Summary of Product Characteristics (SmPC). Available: https://cima.aemps.es/cima/dochtml/ft/80925/FT_80925.html [Accessed 5 May 2017].

11. Government of Catalonia. Department of Health. [Organization Chart: Unit of coordination and strategy of the medicine]. Available:

http://www14.gencat.cat/sacgencat/AppJava/organigrama.jsp?codi=10137\&jq=200001. [Accessed 18 March 2019].

12. O'Brien T, Christrup LL, Drewes AM, et al. European Pain Federation position paper on appropriate opioid use in chronic pain management. Eur J Pain. 2017;21:3-19.

13. Erskine D, Wanklyn S. Opioid safety: striking the right balance. Drug Ther Bull. 2021;59:34.

14. Manchikanti L, Kaye AM, Knezevic NN, et al. Responsible, safe, and effective prescription of opioids for chronic non-cancer pain: American Society of Interventional Pain Physicians (ASIPP) guidelines. Pain Physician. 2017;20:3-92.

15. Chou R, Hartung D, Turner J, et al. Opioid treatments for chronic pain. Comparative effectiveness review No. 229. 2020; [Internet]. AHRQ Publication No. 20-EHC011. Rockville (MD): Agency for Healthcare Research and Quality (US), April 2020.

\section{Figures}




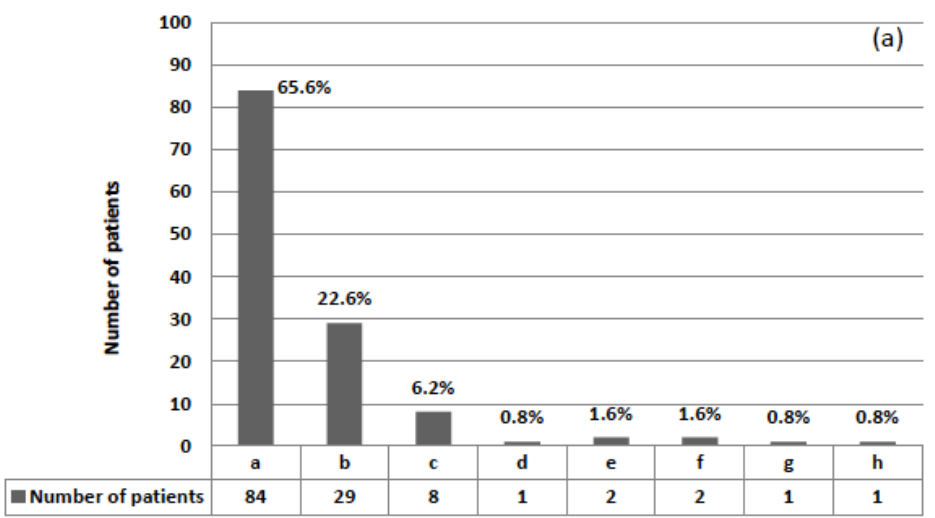

(a: General Practice, b: Traumatology, c: Anesthesia, d: Maxillofacial,

e: Internal Medicine, f: Rheumatology, g: Gynecology, h: Rehabilitation)

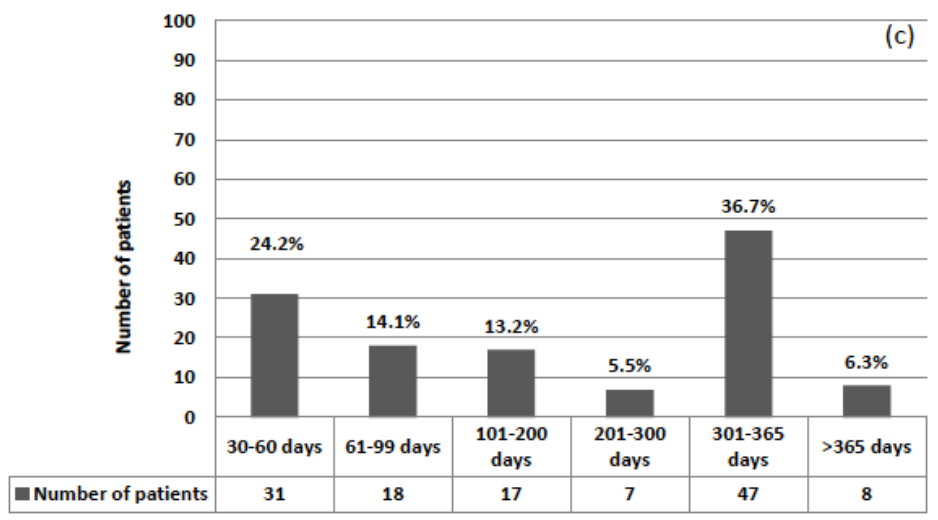

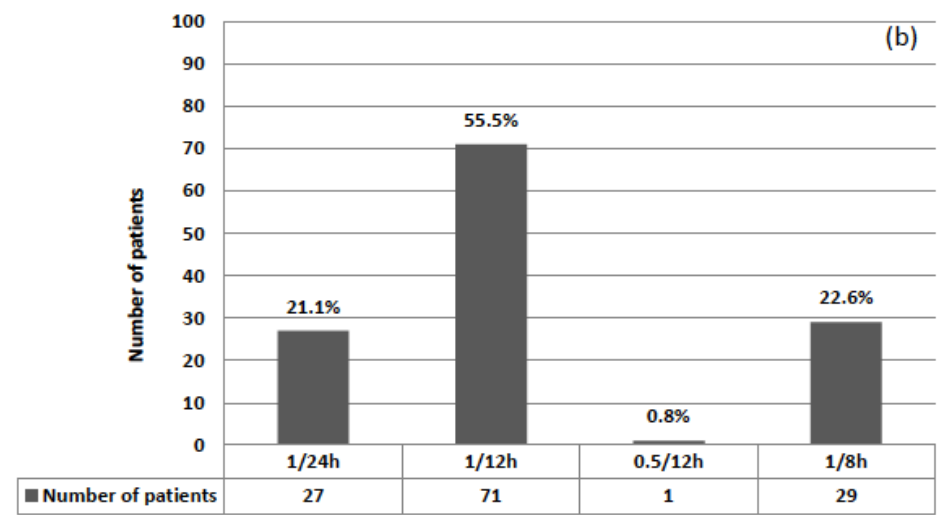

Number of patients

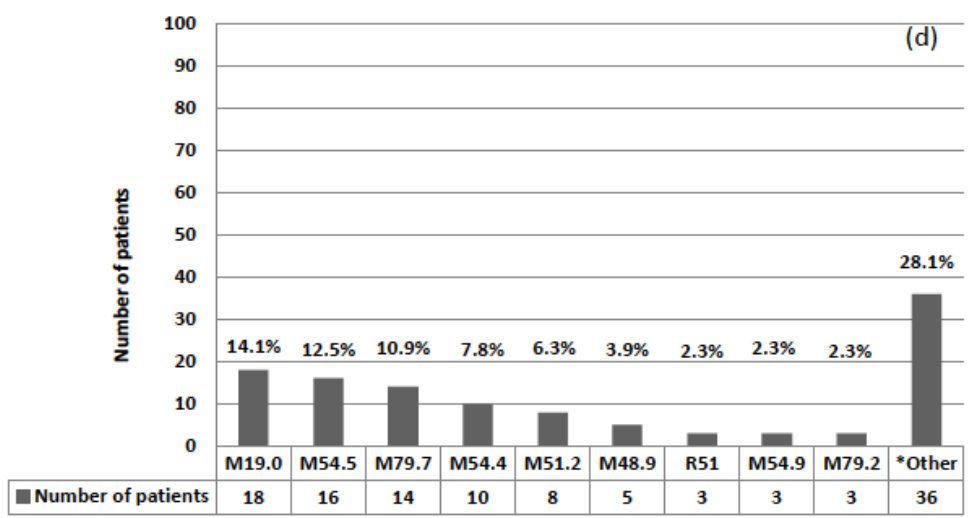

(M19.0: Primary osteoarthritis of other joints; M54.5: Low back pain; M79.7: Fibromyalgia; M54.4: Lumbago with sciatica; M51.2: Other thoracic, toracolumbar and lumbosacral intervertebral disc displacement; M48.9: Spondylopathy, unspecified; R51: Headache; M54.9: Dorsalgia, unspecified; M79.2: Neuralgia and neuritis, unspecified)

\section{Figure 1}

Distribution of patients according to the origin of prescriptions (a); dosing (b); duration of treatment (c); and diagnoses $(\mathrm{d})$. 